\title{
Uma Investigação na Complementaridade do Fluxo de Caixa e do Balanço Financeiro após a Aprovação da NBCASP 16.6 para o Setor Público ${ }^{1}$
}

\section{A Research on Complementary Cash Flow and Balance Sheet after approval of NBCASP 16.6 Public Sector}

\author{
Marcleide Maria Macêdo Pederneiras \\ Professora do Curso de Ciências Contábeis da Universidade Federal da Paraíba, Campus IV \\ Doutoranda em Administração pelo PRODPAD/UFPE.
}

Endereço: Centro de Ciências Aplicadas e Educação - UFPB, Campus IV do Litoral Norte, Centro, CEP: 58800-000

Mamanguape, PB - Brasil, e-mail: marcleide@gmail.com

Juliana Cândida Ribeiro Dias

Mestra - Universidade Federal de Pernambuco - UFPE

Av. dos Funcionários, s/n - Cidade Universitária

CEP 50740-580 - Recife, PE - Brasil, e-mail: juliana cribeiro@yahoo.com.br

Jorge Expedito de Gusmão Lopes

PhD - Universidade Federal de Pernambuco - UFPE

Av. dos Funcionários, s/n - Cidade Universitária, CEP 50740-580 - Recife, PE - Brasil,

e-mail: professorjorgelopes@gmail.com

João Marcelo Alves Macêdo

Professor do Curso de Ciências Contábeis da Universidade Federal da Paraíba, Campus IV

Doutorando em Ciências Contábeis UnB/UFPB/UFRN.

Endereço: Centro de Ciências Aplicadas e Educação - UFPB, Campus IV do Litoral Norte, Centro, CEP: 58800-000

RESUMO

Mamanguape, PB - Brasil, e-mail: marcelo.net@terra.com.br

Este estudo teve por objetivo analisar os ganhos informacionais gerados pela obrigatoriedade na elaboração da Demonstração de Fluxo de Caixa para o setor público após a aprovação da NBCASP 16.6, pois com a mudança o setor público passa a elaborar duas demonstrações com informações financeiras que podem levar ao usuário da Contabilidade Pública a questionar a real necessidade da elaboração destes dois demonstrativos conjuntamente. Para a realização deste estudo foi utilizado o método indutivo, onde foi elaborado um caso prático partindo do Balanço Financeiro do Estado de Pernambuco, através do qual se elaborou a Demonstração de Fluxo de Caixa para comparar as informações geradas por cada demonstrativo. Houve limitação em relação ao caso prático por os municípios ainda não estarem elaborando tais demonstrativos. Após a análise dos demonstrativos concluiu-se que ambos os demonstrativos são importantes para a tomada de decisão dos gestores e que tais demonstrativos são complementares, gerando informações diferentes, havendo, portanto, um ganho informacional para os usuários da contabilidade pública.

Palavras-Chave: Demonstração de Fluxo de Caixa. Balanço Financeiro. Informação Contábil.

\footnotetext{
${ }^{1}$ Revisado pelos pares em 29.08.2013 (blind review). Ajustado e Aceito para publicação em 05.09.2013. Recomendado para publicação por José Ribamar Marques de Carvalho (Editor Científico). Publicado em 15.09.2013. Instituição responsável UACC/CCJS/UFCG.
} 


\section{ABSTRACT}

This study aimed to analyze the gains generated by the informational requirement in the preparation of the Statement of Cash Flows for the public sector after the approval of NBCASP 16.6, with the change because the public sector starts to produce two statements with financial information that may lead to Public Accounting user to question the real need of the elaboration of these two statements together. For this study we used the inductive method, where a case study was prepared based on the balance sheet of the State of Pernambuco, which was drafted by the Statement of Cash Flows to compare the information generated by each statement. There was a limit to the practical case for the municipalities are not yet developing such statements. After analyzing the statements it was concluded that both statements are important for making management decision and that such statements are complementary, leading to different information, therefore there is an informational gain for users of public accounting.

Keywords: Statement of Cash Flows. Balance Sheet. Accounting Information.

\section{INTRODUÇÃO}

O estudo em tela surgiu da observação das mudanças ocorridas no setor público quando o Conselho Federal de Contabilidade (CFC) aprovou as Normas Brasileiras de Contabilidade Aplicadas ao Setor Público - NBCASP dando início a uma revolução na Contabilidade Governamental brasileira.

Esta revolução na normatização da Contabilidade aplicada ao setor público originou-se da necessidade, cada vez maior, de obter informações fidedignas dos entes governamentais e devido ao processo internacional de convergência das práticas contábeis do setor público. Entre as mudanças previstas para a Contabilidade Aplicada ao Setor Público, estão as demonstrações contábeis, com o surgimento, por exemplo, da obrigatoriedade na elaboração do demonstrativo do fluxo de caixa (DFC) para o setor.

A Contabilidade Pública, antes da aprovação da NBCASP 16.6, era regida pela Lei no. 4.320/64, que trazia em seu conteúdo apenas a obrigatoriedade na elaboração de quatro demonstrativos: Balanço Orçamentário, Balanço Financeiro, Balanço Patrimonial e Demonstrações das Variações Patrimoniais. Com a nova norma, foram incluídas a Demonstração de Fluxo de Caixa e do Resultado Econômico.

As reformulações da NBCASP 16.6 trazem agora para o setor público duas demonstrações que evidenciam a situação financeira, o que pode levar certos usuários da Contabilidade Pública a achar desnecessária a elaboração de um ou outro demonstrativo. Pois, para alguns autores, como por exemplo, Nascimento e Cherman (2007), o Balanço Financeiro está para a Contabilidade Pública como à Demonstração do Fluxo de Caixa está para a Contabilidade Empresarial. Esta visão deve-se a semelhança das informações geradas por estes demonstrativos, o que pode levar a crença de que um demonstrativo pode substituir o outro.

Devido às semelhanças das informações surgiu a preocupação em mostrar a importância das informações geradas por cada demonstrativo, bem como evidenciar 
quais as informações adicionais fornecidas por eles, no intuito de demonstrar que ambos os demonstrativos são fontes importantes para o usuário da contabilidade pública conhecer a situação financeira do ente público.

Neste sentido, a pesquisa tentará fazer um estudo sobre o ganho informacional gerado pela obrigatoriedade na elaboração da Demonstração de Fluxo de Caixa para o setor público após a aprovação da NBCASP 16.6.

Este estudo torna-se relevante por tratar de um assunto recente para a Contabilidade pública, que representa para a cidadania o principal instrumento de controle e acompanhamento das ações e das políticas públicas e por tratar das reformulações nas normas públicas que trouxeram mudanças que podem confundir o usuário da contabilidade, principalmente, quanto inclusão da Demonstração de fluxo de caixa no setor público, demonstração que se assemelha ao Balanço Financeiro.

\section{REFERENCIAL TEÓRICO}

\section{Contabilidade Pública e a Necessidade de Mudanças}

A Contabilidade, no Brasil, surgiu, segundo Slomski (2001), no reinado de D. João VI, quando da instalação de seu governo provisório, em 1808, ao publicar o alvará obrigando os Contadores Gerais da Real Fazenda a aplicar o método das partidas dobradas na escrituração mercantil. Em 1850 foi promulgado o Código Comercial, que instituiu a obrigatoriedade da escrituração contábil e da elaboração anual da Demonstração do Balanço Geral. Em 1889, com a queda do Imperador D. Pedro II e conseqüente proclamação da República, surge a necessidade de maior controle das coisas públicas. Assim, em 1922, é aprovado, no Brasil, o código de Contabilidade da União, tendo sido substituído pelo Decreto-lei no 2.416/1940, que instituiu normas para a elaboração da contabilidade dos Estados e Municípios, determinando o modelo-padrão de balanço para as entidades públicas. Este instrumento foi substituído em 1964 pela Lei Complementar no ${ }^{2} .320$.

A prática da contabilidade na Administração Pública regulamentada pela Lei n⿳ 4.320/64 vigora no Brasil por mais de 40 anos, nos quais está lei estatuiu normais de Direito Financeiro para a elaboração e controle dos Orçamentos e elaboração dos balanços da União, dos Estados, dos Municípios e do Distrito Federal.

Porém, nos últimos anos, de acordo com Bugarim (2008), “a Contabilidade brasileira, vem passando por uma grande transformação, demonstrando o dinamismo e a capacidade da profissão contábil em se adaptar aos movimentos da economia mundial globalizada." Ainda segundo Bugarim (2008), "o desenvolvimento crescente de ações e de iniciativas com foco específico na 
Contabilidade Aplicada ao Setor Público é decorrente do anseio da sociedade brasileira por maior transparência na Administração Pública".

A noção de "transparência" no âmbito governamental é cada vez mais empregada em países que defendem o processo democrático de acesso às informações sobre a ação dos gestores públicos em especial no que se refere à política fiscal e à capacidade contributiva. A ênfase a essa abertura constitui um dos alicerces da democracia representativa, pois incentiva o comportamento voltado para o espírito público e inibe a ação dos que se julgam donos da informação. (SILVA, 2009)

Silva (2009) ainda revela a necessidade do tratamento permanente, via sistemas contábeis patrimoniais, por meio do processo de evidenciação ao indicar que:

\footnotetext{
“Em contraponto com a regra da transparência é preciso considerar que os atos produzidos pela execução orçamentária implicam na aquisição ou produção de ativos que, certamente, a partir da sua incorporação ao patrimônio serão capazes de gerar benefícios futuros para o cidadão. Por sua vez, os atos dos administradores também podem constituir obrigações de curto e longo prazo que devem ser registrados no passivo da entidade pública"(SILVA, 2009, p. 7).
}

É nesse contexto que se insere a necessidade da melhor evidenciação dos elementos relativos ao fluxo de caixa permitindo, assim, com base na teoria contábil a separação dos elementos de evidenciação do patrimônio em duas categorias, as contas diferenciais que acumulam valores relativos às contas de receita e despesa com vistas à identificação do resultado do período e as contas integrais que indicam os elementos do ativo (bens e direitos) e passivo (obrigações).

As primeiras são postas em relevo por intermédio da transparência enquanto as segundas estão relacionadas com o processo de evidenciação que significa por em evidencia, ou seja, mostrar com clareza e comprovar de modo insofismável a prática da divulgação (disclousure) de todas as informações positivas ou negativas, que possam influenciar o processo decisório (STN, 2010).

Perante essa demanda por maior controle nas diferentes instâncias da Administração e considerando a dimensão e a diversidade da estrutura dos Poderes da União, o Conselho Federal de Contabilidade editou as Normas Brasileiras de Contabilidade Aplicadas ao Setor Público (NBCASPs). Tais normas surgiram da atuação e inteiração de diversos grupos da sociedade como: profissionais contábeis, professores e entidade reguladora, como o CFC, que procuraram à padronização das práticas e procedimentos contábeis na administração pública, objetivando atender as novas demandas sociais por um novo padrão de informações geradas pela Contabilidade Pública. 
Entre as mudanças previstas para a Contabilidade Aplicada ao Setor Público, estão as demonstrações contábeis, com a aprovação da NBC T 16.6, que traz para o setor público a obrigatoriedade na elaboração de seis demonstrativos, são eles: Balanço Orçamentário, Balanço Financeiro, Balanço Patrimonial , Demonstração da Variações Patrimoniais, Demonstração do Fluxo de Caixa e Demonstração do Resultado Econômico, porém neste estudo serão alvo de nossa análise apenas o Balanço Financeiro e a Demonstração de Fluxo de caixa, por ambas as demonstrações tratarem da evidenciação da situação financeira do ente público.

\subsubsection{Balanço Financeiro}

O Balanço Financeiro, conforme o Art. 103 da Lei $\mathrm{n}^{\circ} 4.320 / 64$, é a demonstração Contábil que evidencia as receitas e as despesas orçamentárias, bem como os recebimentos e os pagamentos de natureza extra-orçamentárias, em um dado exercício financeiro, conjugados com os saldos em espécie proveniente do exercício anterior e os que se transferem para o exercício seguinte, ou seja, visa apresentar o fluxo dos recursos financeiros no ano.

Segundo Kohama (2000), no Balanço Financeiro são demonstrados os movimentos financeiros do exercício, isto é, a somatória das operações realizadas durante o exercício e não o saldo das contas.

O Balanço Financeiro é um quadro com duas seções: Ingressos (Ingressos Orçamentários e Extra-Orçamentários) e Dispêndios (Dispêndios Orçamentários e Extra-Orçamentários), que se equilibram com a inclusão das Disponibilidades do Período Anterior na Seção dos Ingressos, e as disponibilidades para o período seguinte na Seção dos Dispêndios, conforme se pode visualizar no quadro 1.

\begin{tabular}{|c|c|c|c|c|c|}
\hline \multicolumn{6}{|c|}{$\begin{array}{l}\text { ENTE DA FEDERAÇÃO> } \\
\text { BALANÇO FINANCEIRO }\end{array}$} \\
\hline $\begin{array}{l}\text { EXERCÍCIO: } \\
\text { PÁGINA: }\end{array}$ & MÊS & & EMISSÃO: & & \\
\hline \multicolumn{3}{|c|}{ INGRESSOS } & \multicolumn{3}{|c|}{ DISPÊNDIOS } \\
\hline ESPECIFICAÇÃO & $\begin{array}{l}\text { Exercício } \\
\text { Atual }\end{array}$ & $\begin{array}{l}\text { Exercício } \\
\text { Anterior }\end{array}$ & ESPECIFICAÇÃO & $\begin{array}{l}\text { Exercício } \\
\text { Atual }\end{array}$ & $\begin{array}{l}\text { Exercício } \\
\text { Anterior }\end{array}$ \\
\hline $\begin{array}{l}\text { Receita Orçamentária } \\
\text { Ordinária } \\
\text { Vinculada } \\
\text { Saúde } \\
\text { Educação } \\
\text { Previdência Social }\end{array}$ & & & $\begin{array}{l}\text { Despesa Orçamentária } \\
\text { Ordinária } \\
\text { Vinculada } \\
\quad \text { Saúde } \\
\text { Educação } \\
\text { Previdência Social }\end{array}$ & & \\
\hline
\end{tabular}

REUNIR - Revista de Administração, Contabilidade e Sustentabilidade

ISSN: 2237-3667 - Vol.3, no 3, Edição Especial, p. 99-120, 2013. 


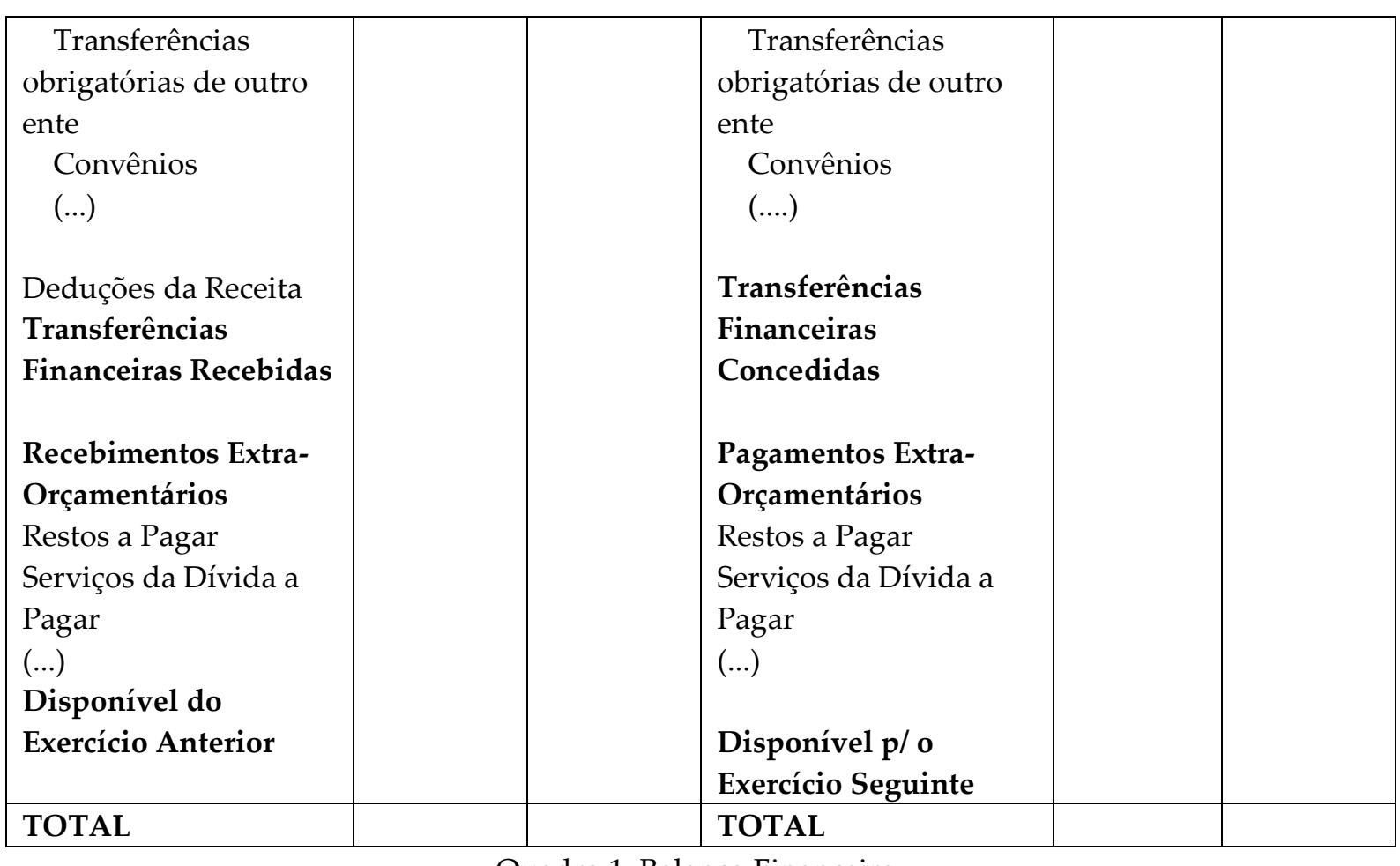

Quadro 1: Balanço Financeiro.

Fonte: Adaptação do Modelo do STN, 2009.

A Coluna da Receita é composta por três grupos de Contas:

10-Receitas Orçamentárias: que representa a receita realizada, ou seja, correspondem aos recolhimentos realizados durante o exercício, a qual é apresentada pelos valores globais por meio de categorias econômicas e fontes. Exemplos: Receitas correntes, Receitas Tributárias, entre outras. Os valores das receitas orçamentárias evidenciados no Balanço Financeiro são os mesmo do Balanço Orçamentário e da Demonstração das Variações Patrimoniais.

2-Recebimentos Extra-Orçamentários: Neste grupo são compreendidos os recebimentos efetuados pelo ente público que constituirão compromissos exigíveis, geralmente, em curto prazo e os recebimentos provenientes de apropriação da despesa orçamentária que foi legalmente empenhada, porém ainda não foi paga. São tipos de Receita Extra-Orçamentária:

- Restos a Pagar: São despesas empenhadas, mas não pagas até o final do exercício. A inscrição em restos a pagar decorre da aplicação do principio da competência para as despesas, bem como pela fase do empenho, pois para se realizar uma despesa esta deve ser empenhada, no intuito de reservar uma parte do orçamento para tal despesa. Quando se reconhece os restos a pagar, está-se 
evidenciando que tal despesa, que ainda não foi paga pertence ao exercício social que terminou.

Segundo Kohama (2000), a composição do Balanço Financeiro deverá demonstrar os valores dos movimentos financeiros, dentro dos quais serão apresentadas as importâncias totais da despesa orçamentária, computando-se a soma das pagas, as incluídas como restos a pagar. Ou seja, a somatória das despesas orçamentárias, consideradas nos movimentos financeiros do exercício, deve ser entendida como efetivamente realizada (empenhada) para efeito do Balanço Financeiro. Por isso, faz-se necessário a inclusão dos restos a pagar como receitas extra-orçamentárias para compensar as despesas orçamentárias, uma vez que com a inscrição dos restos a pagar houve apenas a reserva do recurso, ou seja, este ainda não foi utilizado.

- Serviços da Dívida a Pagar: O serviço da dívida a pagar representa o montante de juros, prêmios e títulos a resgatar, que constitui o serviço da dívida consolidada ou fundada. Como acontece com os restos a pagar, o serviço da dívida é a contrapartida da despesa orçamentária, pois o valor ainda não foi pago.

- Depósitos: Os depósitos referem-se ao montante do valor relativo a recebimentos feitos a título de consignações em folha, como: IRRF, fianças, cauções etc.

- Outras operações: Nesta parte são classificáveis como receitas extraorçamentárias os débitos de tesouraria, as restituições a pagar, os credores, ou seja, são recebimentos feitos e que se constituem em compromissos exigíveis ou são colocados, nesta conta, apenas enquanto aguardam a devida classificação contábil.

3º- Disponível do Exercício Anterior: Por fim, no lado da receita temos o saldo do exercício anterior, que representa o saldo financeiro proveniente do exercício anterior, ou seja, seriam os recursos financeiros que o ente iniciou o exercício atual.

O lado dos Dispêndios também é composto por três grupos, são eles:

10-Despesa Orçamentária: São as despesas provenientes dos compromissos orçamentários, inicialmente assumidos pela emissão de empenho e que por terem se 
transformado em compromissos financeiros, são registrados no sistema financeiro e correspondem à despesa realizada no exercício. As despesas orçamentárias evidenciadas no balanço financeiro são as mesmas do Balanço orçamentário e se deve ao fato das despesas serem registradas de acordo com o regime de competência, ou seja, as despesas orçamentárias são compromissos assumidos no exercício, porém não quer dizer que de fato ocorreu à saída de caixa.

2-Pagamentos Extra-Orçamentários: representa a despesa paga a margem da lei orçamentária do exercício, ou seja, foram recursos que já haviam entrado como ativo financeiro extra-orçamentário e que agora estão sendo pagos ou devolvidos. Exemplos:

- Restos a Pagar: representam o montante financeiro pago durante o exercício, que correspondiam a despesas de exercício anterior.

- Serviços da Dívida a Pagar: Representam a movimentação financeira relativa ao pagamento do montante da amortização, juros e demais encargos da dívida fundada ou consolidada, ou seja, evidencia o efetivo pagamento.

- Depósitos: evidencia o montante dos valores relativos aos pagamentos efetuados durante o exercício, aos consignatórios, ao IRRF, fianças e etc.

- Outras Operações: Nesta parte da despesa extra-orçamentária, identifica-se o montante dos pagamentos efetuados no exercício relativos aos débitos de tesouraria, as restituições a pagar e etc.

3-Disponível para o Exercício Seguinte: São os saldos que passam para o exercício seguinte, que são colocados para compor a parte da conjugação da despesa orçamentária e extra-orçamentária com os saldos que se transferem para o exercício seguinte. Essa conjugação representa, segundo Kohama (2000, p.172), a movimentação financeira global do exercício.

\subsubsection{Informações geradas pelo Balanço Financeiro}

Após a compreensão de como é composta a estrutura do Balanço Financeiro, pode-se analisar quais as informações que este demonstrativo fornece aos usuários da Contabilidade pública. Vejamos a seguir algumas informações importantes que podem ser extraídas deste demonstrativo: 
O Balanço Financeiro evidencia a movimentação financeira das entidades do setor público no período a que se refere, e discrimina:

(a) a receita orçamentária realizada por destinação de recurso;

(b) a despesa orçamentária executada por destinação de recurso;

(c) os recebimentos e os pagamentos extra-orçamentários;

(d) as transferências ativas e passivas decorrentes, ou não, da execução orçamentária; e

(e) o saldo inicial e o saldo final das disponibilidades.

A análise e a verificação do Balanço Financeiro, segundo STN, tem como objetivo predominante prepararos de indicadores que servirão de suporte para a avaliação da gestão financeira.

As informações sobre o fluxo de recursos das disponibilidades são úteis para que os usuários possam tomar decisões que irão influenciar o fluxo de caixa da entidade. Possibilita, ainda, mensurar se o disponível é suficiente para pagar as obrigações referentes aos bens e serviços adquiridos e contratados e ainda satisfazer os gastos de manutenção.

A análise do Balanço Financeiro permite ainda, com a apresentação das receitas e despesas orçamentárias por destinação, a verificação da execução da despesa com as principais vinculações face às respectivas receitas.

É importante mencionar ainda que uma variação positiva na disponibilidade do período não é sinônimo, necessariamente, de bom desempenho da gestão financeira, pois pode acontecer, por exemplo, mediante elevação do endividamento público. Da mesma, forma, a variação negativa na disponibilidade do período não significa, necessariamente, em um mau desempenho, pois pode refletir uma redução no endividamento. Portanto, a análise deve ser feita conjuntamente com o Balanço Patrimonial, considerando esses fatores mencionados e as demais variáveis orçamentárias e extra-orçamentárias.

Além destas informações, é possível verificar através do Balanço Financeiro:

- Vinculações dos recursos - Apresentada as vinculações nas áreas de saúde, educação, previdência social e outras vinculações legais, além da destinação ordinária, de maneira que o grupo de "Outras Vinculações" não ultrapasse 10\% do total da Receita Orçamentária ou Despesa Orçamentária. (MANUAL DO STN, 2009).

- Execução Orçamentária - a partir do Balanço Financeiro é possível saber como foi à execução orçamentária, ou seja, quanto a receita orçamentária representa da despesa orçamentária, evidenciando se houve superávit ou déficit orçamentário. Além disso, mostra o que aconteceu no orçamento, a real execução orçamentária seria a evidenciação de quanto à receita orçamentária 
recebida representa da despesa orçamentária efetivamente paga, considerando, segundo Kohama (2000), o regime de caixa;

- Restos a Pagar - Analisando o Balanço Financeiro é possível calcular o quociente dos Restos a Pagar Inscrito, o que expressa em termos percentuais a relação entre os Restos a Pagar inscrito no exercício, extraídos do Demonstrativo da Disponibilidade de Caixa, do Relatório de Gestão Fiscal; e o total da Despesa Orçamentária, obtida no Balanço Orçamentário. Para Mota (2000) não há parâmetro definido, mas pode ser aceitável um índice que revele um percentual em torno de 5\%, indicando que quase todas as despesas executadas foram pagas no exercício financeiro. Esta análise revela a parcela da Despesa Orçamentária que deixou de ser paga no exercício em análise.

- Situação Financeira - É possível analisar, também, a situação financeira do ente público fazendo a relação entre os recursos financeiros (disponível, créditos, valores realizáveis) com as obrigações financeiras. Para Kohama (2000) o resultado desse quociente será considerado normal quando for igual ou maior que 1, desde que não seja obtido mediante a constituição de dívida fundada. O Autor ainda ressalta que esse quociente deve ser utilizado para verificação da existência, ou não, de "superávit" financeiro apurado no Balanço Patrimonial, atendendo à determinação legal, contida no $\S 2{ }^{\circ}$, do Art. 43, da Lei $\mathrm{n}^{\mathrm{o}} 4.320 / 64$, pois quando o resultado for maior que 1 (superávit), ocorrerá excesso de recursos financeiros que poderá ser utilizado para abertura de créditos adicionais (suplementares e especiais) no exercício seguinte.

\subsection{Demonstração de Fluxo de Caixa}

Fluxo de caixa pode ser compreendido, conforme Gentil (2007) como o movimento de todas as entradas e saídas de recursos financeiros do caixa, ou seja, das origens de caixa, fatores que aumentam o caixa e das aplicações de caixa, que reduzem o caixa da entidade.

Já a Demonstração de Fluxos de Caixa (DFC) pode ser definida, segundo Iudícibus et al (2003) como uma peça contábil que "visa mostrar como ocorreram as movimentações de disponibilidades em um dado período de tempo".

A Demonstração de Fluxo de Caixa pode ser elaborada através de dois métodos: Indireto ou Direto. De acordo com Spadin (2008), o foco desses métodos é o registro da movimentação de caixa das atividades operacionais, uma vez que este é o grupo de atividades que congregará maior volume de informações. 
Segundo Silva (2004) o fluxo de caixa é considerado por muitos analistas um dos principais instrumentos de análise, propiciando-lhes identificar o processo de circulação do dinheiro, por meio da variação das disponibilidades mais as aplicações financeiras. Portanto, sua principal finalidade é fornecer informações acerca do comportamento das disponibilidades financeiras em um determinado período de tempo.

Para Silva (2009) a Demonstração dos Fluxos de Caixa permite aos usuários projetar cenários de fluxos futuros de caixa e elaborar análise sobre eventuais mudanças em torno da capacidade de manutenção do regular financiamento dos serviços públicos.

De acordo com a LRF, no que diz respeito à gestão fiscal é necessário rigor no controle dos recursos públicos, principalmente com os mais líquidos da entidade. Andrade (2002, p. 128), coloca que:

\footnotetext{
“O processo de planejamento econômico e financeiro das entidades públicas passa invariavelmente pela gestão das contas Caixa e Bancos. É notório que essas duas contas têm evidentes provas de liqüidez, estando por isso no rol das mais importantes para a entidade pública, figurando, inclusive, no ápice do plano de contas governamental".
}

Ao tratar da Demonstração do Fluxo de Caixa, a NBCASP (NBC T 16.6), esclarece que se deve evidenciar as movimentações de caixa e equivalentes segregadas nos fluxos:

- Fluxo de caixa das operações: compreende os ingressos, inclusive decorrentes de receitas originárias e derivadas, e os desembolsos relacionados com a ação pública e os demais fluxos que não se qualificam como de investimento ou financiamento;

- Fluxo de caixa dos investimentos: recursos relacionados à aquisição e à alienação de ativo não circulante, bem como recebimentos em dinheiro por liquidação de adiantamentos ou amortização de empréstimos concedidos e outras operações da mesma natureza;

- Fluxo de caixa dos financiamentos: recursos relacionados à captação e à amortização de empréstimos e financiamentos

Andrade (2004) em seu trabalho sugere um modelo de Demonstração de Fluxo de Caixa para a Administração pública, que pode ser visualizado no quadro abaixo: 
<ENTE DA FEDERAÇÃO>

DEMONSTRAÇÃO DOS FLUXOS DE CAIXA

EXERCÍCIO:

MÊS:

EMISSÃO:

PÁGINA:

\begin{tabular}{|c|c|c|c|c|c|}
\hline \multicolumn{3}{|c|}{ INGRESSOS } & \multicolumn{3}{|c|}{ DESEMBOLSOS } \\
\hline ESPECIFICAÇÃO & $\begin{array}{l}\text { Exercício } \\
\text { Atual }\end{array}$ & $\begin{array}{l}\text { Exercício } \\
\text { Anterior }\end{array}$ & ESPECIFICAÇÃO & $\begin{array}{l}\text { Exercício } \\
\text { Atual }\end{array}$ & $\begin{array}{l}\text { Exercício } \\
\text { Anterior }\end{array}$ \\
\hline $\begin{array}{l}\text { DAS OPERAÇÕES } \\
\text { RECEITAS } \\
\text { DERIVADAS } \\
\text { Receita Tributária } \\
\text { Receita de } \\
\text { Contribuições } \\
\text { Outras Receitas } \\
\text { Originárias } \\
\text { RECEITAS } \\
\text { ORIGINÁRIAS } \\
\text { Receita Patrimonial } \\
\text { Receita Agropecuária } \\
\text { (...) }\end{array}$ & & & $\begin{array}{l}\text { DAS OPERAÇÕES } \\
\text { Legislativa } \\
\text { Judiciária } \\
\text { Previdência Social } \\
\text { Administração } \\
\text { Defesa Nacional } \\
\text { Segurança Pública } \\
\text { Relações Exteriores } \\
\text { Assistência Social } \\
\text { Previdência Social } \\
\text { (...) }\end{array}$ & & \\
\hline $\begin{array}{l}\text { Transferências } \\
\text { Intergovernamentais } \\
\text { a Estados } \\
\text { a Municípios }\end{array}$ & & & $\begin{array}{l}\text { Transferências } \\
\text { Intergovernamentais } \\
\text { a Estados } \\
\text { a Municípios }\end{array}$ & & \\
\hline Intragovernamentais & & & Intragovernamentais & & \\
\hline $\begin{array}{l}\text { Fluxo de Caixa Líq. } \\
\text { Positivo das Ativ. } \\
\text { Operacionais }\end{array}$ & & & $\begin{array}{l}\text { Fluxo de Caixa Líq. } \\
\text { Negativo das Ativ. } \\
\text { Operacionais }\end{array}$ & & \\
\hline $\begin{array}{l}\text { DE INVESTIMENTO } \\
\text { Alienação de Ativo } \\
\text { Não Circulante } \\
\text { Amortização de } \\
\text { Empréstimos } \\
\text { Concedidos } \\
\end{array}$ & & & $\begin{array}{l}\text { DE INVESTIMENTO } \\
\text { Aquisição de Ativo } \\
\text { Não Circulante } \\
\text { Concessão de } \\
\text { Empréstimos e } \\
\text { Financiamentos } \\
\end{array}$ & & \\
\hline $\begin{array}{l}\text { Fluxo de Caixa Líq. } \\
\text { Positivo das Ativ. } \\
\text { Investimento }\end{array}$ & & & $\begin{array}{l}\text { Fluxo de Caixa Líq. } \\
\text { Negativo das Ativ. } \\
\text { Investimento }\end{array}$ & & \\
\hline $\begin{array}{l}\text { DE } \\
\text { FINANCIAMENTO } \\
\text { Operações de Crédito }\end{array}$ & & & $\begin{array}{l}\text { DE } \\
\text { FINANCIAMENTO } \\
\text { Amortização/Refinanci } \\
\text { amento da Dívida }\end{array}$ & & \\
\hline $\begin{array}{l}\text { Fluxo de Caixa Líquido } \\
\text { Positivo das Ativ. } \\
\text { Financiamento }\end{array}$ & & & $\begin{array}{l}\text { Fluxo de Caixa Líq. } \\
\text { Negativo das Ativ. de } \\
\text { Financiamento }\end{array}$ & & \\
\hline
\end{tabular}




\begin{tabular}{|l|l|l|l|l|}
\hline $\begin{array}{l}\text { GERAÇÃO LÍQUIDA } \\
\text { POSITIVA DE CAIXA }\end{array}$ & & $\begin{array}{l}\text { GERAÇÃO LÍQUIDA } \\
\text { NEGATIVA DE } \\
\text { CAIXA }\end{array}$ & & \\
\hline CAIXA E & & CAIXA E & & \\
EQUIVALENTE DE & EQUIVALENTE DE & & \\
CAIXA DO & CAIXA PARA O & & \\
ANTERIOR & EXERCÍCIO & & \\
\hline $\begin{array}{l}\text { DISPONIB } \\
\text { COMPENSATÓRIAS } \\
\text { EX. ANTERIOR }\end{array}$ & & $\begin{array}{l}\text { DISP. } \\
\text { COMPENSATÓRIAS }\end{array}$ & & \\
\hline $\begin{array}{l}\text { DISPONIBILIDADE } \\
\text { DO EX. ANTERIOR }\end{array}$ & & P/ EX SEGUINTE & & \\
& & DISPONIBILIDADE & & \\
& & PARA O EX. & & \\
SEGUINTE & & \\
\hline
\end{tabular}

Quadro 2: Demonstração do Fluxo de Caixa

Fonte: Adaptação do modelo do Manual do STN, 2009.

Segundo Andrade (2008), no fluxo de caixa da gestão pública podem ser observados casos específicos de sazonalidades como inadimplência de contribuintes, potencial de investimento, vinculação de recursos, projeção para futuro a curto, médio e longo prazo, demonstração em valores constantes e valores correntes, vencimentos por ordem cronológica dos desembolsos, controle do grau de endividamento, indicadores de liquidez, visão geral da situação das finanças públicas, entre outros.

Andrade (2008) recomenda que o fluxo de caixa seja trabalhado com pelo menos dois exercícios financeiro anteriores e um exercício financeiro à frente, projetando-se, onze meses à frente do mês base de cálculo, critério atualmente adotado pela LRF para apuração da receita corrente líquida e de gastos com pessoal.

A elaboração do fluxo financeiro pode ajudar o gestor a decidir onde alocar os recursos financeiros, uma vez que o planejamento e o controle permitirão que o gestor possa conhecer como os recursos estão empregados, evitando a busca de recursos de terceiros, ou seja, os empréstimos, por meio de antecipação de receitas orçamentárias ou mesmo financiamentos em longo prazo.

\subsubsection{Informações geradas pela Demonstração de Fluxo de Caixa}

A Demonstração dos Fluxos de Caixa visa à análise do desempenho financeiro do setor público, permitindo:

- ter uma visão geral da situação das finanças públicas, possibilitando efetuar comparações entre ingressos e desembolsos por tipos de atividades (operacionais, de 
investimento e de financiamento), e avaliar as decisões de investimento e financiamento público;

- avaliar a situação presente e futura do caixa da entidade, permitindo análise de liquidez;

- certificar se os excessos de caixa estão sendo devidamente aplicados;

- conhecer a capacidade de expansão das despesas com recursos próprios gerados pelas operações;

- analisar o emprego dos recursos financeiros disponíveis da melhor forma possível;

- a análise imediata da disponibilidade e do impacto da mesma nas finanças da entidade, quando da inserção de nova despesa na programação;

- avaliar a previsão de quando é possível contrair novas despesas sem que isso comprometa as finanças públicas;

- o controle sobre a ociosidade ou sobre o uso abusivo de recursos em determinados tipos de despesas;

- evitar o déficit público e aumento do endividamento público.

Além destas informações, é possível verificar através da Demonstração de Fluxo de Caixa:

\section{Alternativas para Investimentos}

Segundo Matarazzo (2003), com o fluxo de caixa é possível avaliar alternativas para investimento; avaliar e controlar ao longo do tempo as decisões importantes que são tomadas na empresa, com reflexos monetários; avaliar a situação presente e futura do caixa da empresa, posicionando-a para que não chegue a situações de iliquidez; certificar que os excessos momentâneos de caixa estão sendo devidamente aplicados.

\section{Avaliar a aplicação dos recursos}

Zdanowicz (1998) diz que é possível o gestor verificar a melhor forma possível de empregar os recursos financeiros disponíveis, evitando que fiquem ociosos e estudando, antecipadamente, a melhor aplicação, o tempo e a segurança dos mesmos. 


\section{Situação Financeira}

Segundo Andrade (2004) com a demonstração de fluxo de caixa é possível o gestor público ter as seguintes informações:

- analisar do desempenho financeiro da entidade;

- saber a capacidade de expansão com recursos próprios gerados pelas operações, integra as demais demonstrações financeiras;

- verificar a auto-suficiência de seus compromissos assumidos, capacidade de expansão, independência financeira;

- ter uma visão geral da situação das finanças públicas;

- permitir o emprego dos recursos financeiros disponíveis da melhor forma possível;

- permitir análise imediata da disponibilidade e do impacto da mesma nas finanças da entidade, quando da inserção de nova despesa na programação;

- permitir a previsão de quando é possível contrair novas despesas sem que isso comprometa as finanças;

- permitir o controle sobre a ociosidade ou sobre o uso abusivo de recursos;

- visualizar e saldar obrigações na data do vencimento;

- evitar desembolsos vultosos sem disponibilidade financeira; e

- evita o déficit público e consequentemente dívidas.

\section{PROCEDER METODOLÓGICO}

O desenvolvimento deste artigo, principalmente, no que se refere à análise das inovações apresentadas pelas NBCASP 16.6, utilizou como técnica de pesquisa, a documentação indireta (Lakatos Marconi, 1991), na qual foi feito uso de uma vasta revisão bibliográfica consultando livros, revistas especializadas, publicações em meios eletrônicos, artigos, periódicos e essencialmente a legislação adequada.

Em relação ao método de abordagem, foi utilizado o indutivo, conforme Lopes (2006), o método de abordagem é indutivo, quando se chega a conclusões gerais partindo de dados específicos, ou seja, para se chegar a evidenciação da importância da inclusão das demonstrações de Fluxo de Caixa para a geração de informações claras, compreensíveis e transparentes para o usuário da Contabilidade pública, partiu-se da análise dos resultados apresentados por estes demonstrativos, em resumo, o método indutivo foi o que mais se adaptou a este caso.

Para a análise do estudo foi utilizado o balanço financeiro do Governo do Estado de Pernambuco em 2008 e a partir de dados fornecidos pelo ente foi elaborada a demonstração de Fluxo de caixa, uma vez que este demonstrativo ainda não foi elaborado pela entidade, pois a obrigatoriedade para elaboração é a partir de 
2010. Após as demonstrações prontas, foram analisadas as informações que podem ser extraídas de cada demonstrativo, no intuito de concluir sobre a complementaridade das informações, bem como verificar a importância de cada demonstrativo para o setor público.

\section{CASO PRÁTICO: ANÁLISE DA SITUAÇÃO FINANCEIRA DO GOVERNO DO ESTADO DE PERNAMBUCO}

Depois de abordados o conceito de cada demonstração, neste ponto será elaborado um exemplo prático com esses dois demonstrativos, buscando evidenciar se eles ajudariam o gestor a entender a situação financeira do ente público. Para isto, foi analisado o Balanço Financeiro do Estado de Pernambuco, disponível no site do Governo do Estado de Pernambuco, e a partir dele foi elaborado uma Demonstração de Fluxo de Caixa simplificada, pois algumas informações não foram possíveis de serem verificadas, porém nada que comprometa o exemplo.

A seguir (tabela 1) pode-se visualizar o Balanço Financeiro do Estado de Pernambuco, através dos quais os gestores podem tirar algumas informações importantes sobre a Gestão financeira do Estado.

\begin{tabular}{|c|c|c|c|}
\hline \multicolumn{4}{|c|}{$\begin{array}{l}\text { GOVERNO DO ESTADO DE PERNAMBUCO } \\
\text { BALANÇO FINANCEIRO }\end{array}$} \\
\hline \multicolumn{2}{|c|}{ INGRESSOS } & \multicolumn{2}{|c|}{ DISPÊNDIOS } \\
\hline ESPECIFICAÇÃO & Valores & ESPECIFICAÇÃO & Valores \\
\hline Receita Orçamentária & $14.348 .872,00$ & Despesa Orçamentária & $13.938 .133,00$ \\
\hline Receitas Correntes & $15.261 .991,00$ & Legislativa & $336.701,00$ \\
\hline Receita Tributária & $7.120 .434,00$ & Judiciárias & $557.479,00$ \\
\hline Receita de & $2.073 .565,00$ & Administração & $726.926,00$ \\
\hline \multicolumn{4}{|l|}{ Contribuições } \\
\hline Receita Patrimonial & $205.819,00$ & Segurança Pública & $1.154 .780,00$ \\
\hline Receita Agropecuária & 592,00 & Assistência Social & $26.037,00$ \\
\hline Receita Industrial & $1.440,00$ & Previdência Social & $1.977 .157,00$ \\
\hline Receita de Serviços & $177.374,00$ & Saúde & $2.241 .033,00$ \\
\hline Transferências & $5.460 .264,00$ & Trabalho & $125.398,00$ \\
\hline \multicolumn{4}{|l|}{ Correntes } \\
\hline Outras Receitas & $222.502,00$ & Educação & $1.617 .919,00$ \\
\hline \multicolumn{4}{|l|}{ Correntes } \\
\hline & & $\begin{array}{l}\text { Cultura } \\
\text { Direitos da Cidadania }\end{array}$ & $\begin{array}{l}102.429,00 \\
316,535,00\end{array}$ \\
\hline $\begin{array}{l}\text { Receitas de Capital } \\
\text { Operações de Credito }\end{array}$ & $\begin{array}{l}\mathbf{5 5 5 . 7 9 4 , 0 0} \\
117.566,00\end{array}$ & $\begin{array}{l}\text { Direitos da Cidadania } \\
\text { Urbanismo }\end{array}$ & $\begin{array}{r}316.535,00 \\
88.128,00\end{array}$ \\
\hline Internas & & & \\
\hline $\begin{array}{l}\text { Operações de Credito } \\
\text { Externas }\end{array}$ & $95.643,00$ & Habitação & $29.939,00$ \\
\hline
\end{tabular}




\begin{tabular}{|c|c|c|c|}
\hline $\begin{array}{l}\text { Alienação de Bens } \\
\text { Moveis }\end{array}$ & $3.165,00$ & Saneamento & $297.551,00$ \\
\hline Moveis & & & \\
\hline Alienação de Bens & 79,00 & Gestão Ambiental & $30.289,00$ \\
\hline Imóveis & & & \\
\hline Amort. de Emprést e & 165,00 & Ciência e Tecnologia & $40.223,00$ \\
\hline Financ & & & \\
\hline Transferências de & $282.236,00$ & Agricultura & $199.265,00$ \\
\hline Capital & & & \\
\hline $\begin{array}{l}\text { Outras Receitas de } \\
\text { Capital }\end{array}$ & $56.941,00$ & Organização Agrária & $2.255,00$ \\
\hline & & Indústria & $112.417,00$ \\
\hline & & Comércio e Serviços & $105.895,00$ \\
\hline Deduções da Receita & $(1.468 .913,00)$ & Comunicações & $1.445,00$ \\
\hline & & Energia & 247,00 \\
\hline & & Transporte & $330.360,00$ \\
\hline & & Desporto e Lazer & $9.553,00$ \\
\hline & & Encargos Especiais & $3.508 .172,00$ \\
\hline Receitas Extra- & $11.359 .484,00$ & Despesas Extra- & $11.214 .826,00$ \\
\hline Orçamentárias & & Orçamentárias & \\
\hline Restos a Pagar & $582.858,00$ & Restos a Pagar & $534.173,00$ \\
\hline Restos a Pagar & $490.462,00$ & Restos a Pagar Processados & $487.113,00$ \\
\hline Processados & & & \\
\hline Restos a Pagar Não & $92.396,00$ & Restos a Pagar Não Proc. & $47.060,00$ \\
\hline Proc. & & & \\
\hline Pessoal a Pagar & $79.154,00$ & Pessoal a Pagar & $36.604,00$ \\
\hline Consignações & $1.446 .298,00$ & Consignações & $1.357 .423,00$ \\
\hline Depósitos de Origens & $2.098 .775,00$ & Depósitos de Origens Div. & 2.031.774,00 \\
\hline Diversas & & & \\
\hline Valores Pendentes & 2.679.901,00 & Valores Pendentes Exigíveis & $2.661 .048,00$ \\
\hline Exigíveis & & & \\
\hline Recebimentos de Ativos & & Devolução de Outros & \\
\hline Financeiros & $4.472 .294,00$ & Passivos Financeiros & \\
\hline Outras Inscrições & 204,00 & Const. de Ativos Financeiros & $4.591 .978,00$ \\
\hline & & Outras Baixas & $1.826,00$ \\
\hline Saldo do Exercício Anterior & $1.050 .863,00$ & $\begin{array}{l}\text { Saldo para o Exercício } \\
\text { Seguinte }\end{array}$ & $1.606 .260,00$ \\
\hline Disponível & $944.113,00$ & Disponível & $1.440 .718,00$ \\
\hline Caixa & 380,00 & Caixa & 51,00 \\
\hline Banco c/ Movimento & $629.556,00$ & Banco c/ Movimento & $884.964,00$ \\
\hline Aplicações Financeiras & $274.851,00$ & Aplicações Financeiras & $513.662,00$ \\
\hline Banco c/ Vinculadas & $39.326,00$ & Banco c/ Vinculadas & $42.040,00$ \\
\hline Investimentos RPPS & $106.750,00$ & Investimentos RPPS & $165.542,00$ \\
\hline TOTAL & $26.759 .219,00$ & TOTAL & 6.759.219,00 \\
\hline
\end{tabular}

Tabela 1 - Balanço Financeiro do Estado do Pernambuco.

Fonte: Secretaria da Fazenda do Estado do Pernambuco, 2008. 
$\Rightarrow$ Observa-se que a estrutura do balanço Financeiro difere um pouco da nova estrutura aprovada pela NBCASP 16.6;

$\Rightarrow$ a receita orçamentária realizada por destinação de recurso foi de R $\$$ 15.261.991,00 de Receitas Correntes que serão poderão ser utilizados para despesas correntes do exercício e também poderão ser utilizadas para cobrir despesas de capital e de $\mathrm{R} \$ 555.794,00$ de Receitas de Capital para serem utilizadas em despesas voltadas a despesas de Capital, porém é importante observar que as receitas de capital não podem ser utilizadas para cobrir despesas correntes, pois o Estado estaria se desfazendo de bens para cobrir despesas de custeios contrariando, deste modo, a denominada regra de ouro das finanças públicas.

$\Rightarrow$ pode-se observar a despesa orçamentária executada por destinação de recurso, onde se verifica quais os setores que o Governo mais utilizou os recursos, por exemplo, Saúde, Previdência Social,Segurança Pública e Educação;

$\Rightarrow$ evidencia também os recebimentos extra-orçamentário decorrente de terceiros e que são exigíveis, como também os restos a pagar que reflete as despesas empenhadas e que não foram pagas, servindo para o gestor verificar que os recursos em caixa não estão disponíveis, pois já estão empregados e por fim os pagamentos extra-orçamentários, que evidenciam destes recursos exigíveis quais foram realizados no exercício;

$\Rightarrow$ as transferências ativas e passivas decorrentes, ou não, da execução orçamentária; e;

$\Rightarrow$ o saldo inicial e o saldo final das disponibilidades.

Analisando o fluxo de caixa elaborado a partir do Balanço Financeiro podemse observar as seguintes questões (tabela 2):

\begin{tabular}{lc}
\hline \multicolumn{2}{c}{ FLUXO DE CAIXA } \\
\hline \multicolumn{2}{c}{$\mathbf{1 . 0 5 0 . 8 6 3 , 0 0}$} \\
\hline Saldo Inicial & \\
DAS OPERAÇÕES & $7.120 .434,00$ \\
Receitas Correntes & $2.073 .565,00$ \\
Receita Tributária & \\
Receita de Contribuições & $205.819,00$ \\
Outras Receitas Derivadas & 592,00 \\
Receita Patrimonial & $1.440,00$ \\
Receita Agropecuária & $177.374,00$ \\
Receita Industrial & \\
Receita de Serviços &
\end{tabular}




\begin{tabular}{lr} 
Outras Receitas Originárias & $222.502,00$ \\
Remuneração das Disponibilidades & $56.941,00$ \\
DEDUÇÃO DO FUNDEB & $(\mathbf{1 . 4 6 8 . 9 1 3 , 0 0 )}$ \\
(-) Despesas Orçamentárias & $(13.938 .134,00)$ \\
(+) Receitas Extra-orçamentárias & $11.359 .484,00$ \\
(-) Despesas Extra-orçamentárias & $(11.214 .825,00)$ \\
Transferências & \\
Correntes & $5.460 .265,00$ \\
Capital & $282.236,00$ \\
Fluxo de Caixa Líquido Positivo das & \\
Atividades Operacionais & $\mathbf{3 3 8 . 7 7 9 , 0 0}$ \\
\hline DE INVESTIMENTO & $3.244,00$ \\
Alienação de Ativo Não Circulante & 165,00 \\
Amortização de Empréstimos Concedidos & \\
Fluxo de Caixa Líquido Positivo das & $\mathbf{3 4 2 . 1 8 8 , 0 0}$ \\
Atividades de Investimento & \\
\hline DE FINANCIAMENTO & $213.208,00$ \\
Operações de Crédito & \\
Fluxo de Caixa Líquido Positivo das & $\mathbf{5 5 5 . 3 9 6 , 0 0}$ \\
Atividades de Financiamento & $\mathbf{1 . 6 0 6 . 2 6 0 , 0 0}$ \\
\hline GERAÇÃO LÍQUIDA POSITIVA DE & $\mathbf{3}$ \\
CAIXA & \\
\hline SALDO FINAL DO CAIXA & \\
\hline
\end{tabular}

Tabela 2 - Balanço Financeiro do Estado do Pernambuco.

Fonte: Secretaria da Fazenda do Estado do Pernambuco, 2008.

$\Rightarrow$ Quais os recursos que são decorrentes da operação do Estado, ou seja, decorrente da força coercitiva, como impostos, taxas e etc;

$\Rightarrow$ Possibilita verificar se a geração de caixa foi decorrentes de alienação de bens, o que faz com que o gestor público analise a sua capacidade de liquidez;

$\Rightarrow$ Verificar se o Estado conseguiu cobrir suas despesas correntes utilizando as receitas correntes;

$\Rightarrow$ Que do saldo Final de Caixa, 61\% foi gerado pelas operações do Estado, 06\% pela alienação e amortização de empréstimos e 0,38\% foi decorrente de operação de crédito;

$\Rightarrow$ A partir fluxo de caixa do Estado de Pernambuco, observa-se que a geração de recursos financeiros da entidade é decorrente das operações do Estado, o que permite ao gestor prever a possibilidade de realizar novas despesas;

A Demonstração de Fluxo de caixa irá permitir, também, o gestor verificar a evolução financeira do ente de um ano para o outro, uma vez que a demonstração irá evidenciar valores de dois anos. 


\section{CONSIDERAÇÕES FINAIS}

A questão básica desta pesquisa era obter, com base nos dados coletados junto às demonstrações do Governo do Estado de Pernambuco, a resposta que permitisse conhecer a complementaridade das informações gerada pela Demonstração de Fluxo de Caixa e o Balanço Financeiro para os usuários da Contabilidade Pública após a NBCASP 16.6.

Devido às semelhanças das informações surgiu a preocupação em mostrar a importância das informações geradas por cada demonstrativo, bem como evidenciar quais as informações adicionais fornecidas por eles, no intuito de demonstrar que ambos os demonstrativos são fontes importantes para o usuário da contabilidade pública conhecer a situação financeira do ente público.

A análise dos demonstrativos revelou que ambos os demonstrativos são importantes para a tomada de decisão dos gestores e que os mesmos são complementares além de gerarem informações diferentes. Neste sentido um não pode ser substituído pelo outro sob pena da perda de informações relevantes tanto para o processo decisório, como para os usuários da informação pública.

Diante disto, o ganho informacional para o setor público é a existência de dois demonstrativos que permitem aos usuários da contabilidade pública conhecer a situação financeira, verificando tanto a questão relacionada aos ingressos e dispêndios financeiros, mas também avaliar as questões relacionadas à capacidade de investimento, a qualidade dos gastos feitos pelos gestores, bem como ter uma visão geral da situação das finanças públicas.

A pesquisa ainda revelou que as mudanças da contabilidade aplicada ao setor público vieram no intuito de trazer maior transparência na utilização dos recursos públicos.

\section{REFERÊNCIAS}

ANDRADE, Nilton de Aquino. Contabilidade pública na gestão municipal. São Paulo: Atlas, 2002.

ANDRADE, Nilton de Aquino; BATISTA, Daniel Gerhard; SOUZA, Cleber Batista. O planejamento como base da contabilidade para a gestão pública. Porto alegre: Revista do CRC/RS, no 116, 2004.

ANGÉLICO, João. Contabilidade pública. 8. ed. São Paulo: Atlas,1994; 
BRASIL. Lei no 10.406/02. Institui o Código Civil. Diário Oficial da República Federativa do Brasil, Poder Executivo, Brasília, DF, 11 de jan. 2002.

. Lei Ordinária n. ${ }^{\circ}$ 4.320, de 17 de março de 1964. Institui Normas Gerais de Direito Financeiro para elaboração e controle dos orçamentos e balanços da União, dos Estados, dos Municípios e do Distrito Federal. Diário Oficial da República Federativa do Brasil, Poder Executivo, Brasília, DF, 23 de mar. 1964. Disponível em: http://www.planalto.gov.br/ccivil 03/leis/14320.htm. Acesso: 24 de fev. 2008.

Secretaria do Tesouro Nacional - STN. Manual de Contabilidade Pública Aplicada ao Setor Público -Demonstrações Contábeis do Setor Público, vol. 5, 2a edição, 2009.

CONSELHO FEDERAL DE CONTABILIDADE. Normas Brasileiras aplicada ao setor público. Disponível em: http://www.cfc.org.br. Acesso em: 23 de fev. 2008.

GENTIL, Eduardo Diener. Gestão do capital de giro. Disponível em: <http://www.administradores.com.br/artigos/gestao_do_capital_de_giro/11357/>.

Acesso em: 26/04/2009.

KOHAMA, Hélio. Contabilidade pública: teoria e prática. 10. ed. São Paulo: Atlas, 2006.

KOHAMA, Hélio. Balanços Públicos. 7. ed. São Paulo: Atlas,2000.

IUDÍCIBUS. Sérgio de; MARTINS, Eliseu; GELBCKE, Ernesto Rubens. Manual de contabilidade das sociedades por ações. 6. ed. São Paulo: Atlas, 2003.

LAKATOS, Eva Maria;MARCONI, Marina de Andrade. Metodologia do trabalho cientifico. São Paulo: Atlas, 2001.

LOPES, Jorge. O fazer do trabalho científico em ciências sociais aplicadas. Recife: Ed. Universitária da UFPE, 2006.

SILVA, Lino Martins. NBCASP: A grande reforma na Contabilidade Pública. Disponível no Blog do Prof. Lino Martins da Silva. Disponível em: www.linomartins.wordpress.com. Acesso em: 11 jun. 2009.

MATARAZZO, Dante Carmine. Análise financeira de balanços: abordagem gerencial. São Paulo:Atlas, 2003. 
MOTA, Francisco Glauber Lima. Curso Básico de Contabilidade Pública. 2.ํa ed. Brasília, 2006.

NASCIMENTO, Leonardo Silveira. A elaboração das Normas Brasileiras de Contabilidade aplicadas ao Setor Público: Análise à luz dos Princípios Contábeis. IN: $2^{\circ}$ CONGRESSO UFSC DE CONTROLADORIA E FINANÇAS, 2008, Florianópolis/SC. Anais... Florianópolis/SC, 2008.

SILVA, Lino Martins da. Contabilidade governamental: um enfoque administrativo da nova Contabilidade Pública. 8ª . ed. São Paulo: Atlas, 2009.

SPADIN, Carlos Eduardo. A Importância da Demonstração dos Fluxos De Caixa Enquanto Instrumento Gerencial Para A Tomada De Decisão. Revista de Ciências Gerenciais, v. 12, no. 14, Ano 2008.

ZDANOWICZ, José Eduardo. Fluxo de Caixa: Uma Decisão de Planejamento e Controle Financeiros. Porto Alegre: Sagra Luzzatto, 1998.

PERNAMBUCO. Secretaria da Fazenda do Estado do Pernambuco. Balanço Geral do Estado de Pernambuco, 2008. Disponível em: http://www.sefaz.pe.gov.br/flexpub/versao1/filesdirectory/sessions4012.pdf. Acesso em: 10 jun. 2009. 